\title{
THE MANAGEMENT OF CHANGE IN ELECTRONIC LIBRARIES
}

\author{
John Akeroyd \\ Learning and Information Services \\ South Bank University \\ Borough Road \\ London SE1 OAA \\ akeroyj@sbu.ac.uk
}

\begin{abstract}
Libraries are in a process of fundamental change brought about by radical developments in technology. This paper makes some assumptions as to how the future will look, addresses the barriers to increased use of technology and finally looks at what managers need to do to bring about these changes and reviews the relevant key issues.
\end{abstract}

"I have seen the future and brother it is murder"

"Things are gonna slide in all directions..."

Leonard Cohen: The Future

\section{Introduction}

My starting point in this discussion is the notion of the digital library which, despite much research and many scholarly articles remains ill-defined and illusive. I want to try and model the digital library and to that end will attempt to describe a generic model for any library. Peter Brophy, an eminent UK authority constructed a theoretical model which might apply to any library in a paper in 2000 . He built upon what he refers to as the common mission - to enable users to gain access to the information that they need (Brophy 2000). Brophy proposed - on the one hand a universe of information which is adequately organised and using metadata as a document surrogate and on the other, a universe of users sub-divided to specific user populations. The function of the library as he sees it is - through its core processes - is to bring these together. This is a highly mechanistic view and to some extent overlooks the subsidiary and associated roles of libraries, such as training and user support, which are likely to predominate as the core processes are effectively automated out of the system. But it is helpful in informing some of the functions a library needs to perform in the future. As Brophy says "libraries will be based on new paradigms of service and whilst traditional functions will not be discarded wholesale, libraries will be much more active participants in the exploitation and the organisation of information and knowledge". So the point is not that the fundamental purpose of libraries is changing but that the relative importance of different functions, given a different context, is shifting.

Critical to the current generation of digital libraries has been the steady progress in computerisation of all or most aspects of library functions, beginning in the early $70 \mathrm{~s}$ 
with computerised library catalogues, and moving through the development of circulation systems, to the development of the integrated library systems which appeared in many advanced libraries towards the end of the late 70's and early 80 's. These integrated systems use a single, software architecture to manage the core processes of libraries including cataloguing, circulation, acquisitions, and financial control and, with varying degrees, other associated but perhaps less critical functions such as inter-library loans and management information. One of the biggest milestones over this period was the development of the OPAC which revolutionised catalogue searching and first brought about the notion that libraries could, somehow, be distributed and that catalogues did not necessarily represent just the stock held within that particular building.

ILMS have continued to develop this mixture of highly sophisticated functions but alongside these has been the parallel emergence of other systems concerned with the delivery of information to the users. Critical has been the development of online information delivered through stand-alone and then networked CD-ROMs and now through remote servers. Many of these have, in turn, been re-emerging as web compliant databases providing even an average library with the opportunity to search enormous collections of data.

Libraries have had to encompass these emerging services and generally embrace them within a traditional library framework. This need - to be able to deal with conventional books and journals on one hand and electronic resources on the other - has given rise to what has become known as the hybrid library (Rusbridge 1998) - the notion being that it must at one and the same time deal with both a plurality of licensed electronic resources, often with different interfaces and search engines, including web resources through search engines or portals, and yet, in parallel, manage traditional library books and their circulation. The scale of this challenge is extraordinary and as a consequence there are a number of technical barriers, which stand in the way of the development of the digital library, and it is to these that I shall now turn.

The first is this issue of integration. Highly developed libraries can quote a whole series of discreet services built up over the recent past, which in many ways serve to confuse and baffle our users. In my own library I could quote probably as many as 18 interfaces including: the catalogue, several CD-ROM systems (each of which have a different proprietary interface), web based services, Internet search engines, gateway services, portals, intranet information retrieval systems, etc. There is a distinct lack of uniformity in the approach so that users are faced with learning a multiplicity of search systems to undertake even a small-scale literature search, particularly if they are working in cross disciplinary areas. Thus digital libraries are dealing with a distributed environment where users require seamless access to resources which might be distributed and heterogeneous. What is usually advocated, is a single point of access to a totality of digital library collections. Such systems would retrieve a relevant set of references together with suitable annotations, be adequately de-duplicated and effectively ranked Some levels of integration have been achieved, particularly through the web itself, although that only offers integration at a rather shallow level. 
There are a number of critical developments which are going towards resolving the multiple resource/single point of access challenge. Many are the subject of considerable research effort worldwide at the moment. They include, for example: the development of metadata systems capable of acting as effective resource surrogates at various levels (for example, from collection description right down to individual web page), and those in the context of different disciplines and the resources. The European Commission has put effort into looking at ways of inter-operating with different metadata schema and resolving these to provide a seamless approach as far as the user is concerned. In the same way, has been the development of common search protocols such as Z39.50; which is best known in the library community but suffers somewhat from only being accepted within that community. There is a view that there will be a gradual migration of Z39.50 towards an XML implementation, which in turn implies it will be much easier to adopt in the context of XML systems generally.

Many of these developments have been wrapped into what has become known as resource brokers, intermediate systems which can perform a whole number of functions between the user and the resource they are attempting to search. So that as far as the user is concerned they are presented with a single set of unified resources in the response to a query instead of consecutively having to search a number of data base systems. There are now a number of commercial products which perform this function, some integrated within integrated library management systems; others such as Metalib can act as standalone systems.

Meanwhile, outside the library sector we have seen the emergence of a multiplicity of technologies that are radically altering the way in which general users both regard and use information. These include exceptionally powerful Internet search engines, capable on the one hand of identifying astonishing amounts of garbage, but also capable of the most intricate levels of retrieval of quality resources with both speed and efficiency. Such search engines are challenging traditional library mechanisms as rapid gateways to information resources. Other developments have included harvesting agents, which can trawl distributed sites and collate the results into high-quality and highly personalised subsets. And finally has been the re-emergence of SDI or alerting systems as they now tend to be known, which are customisable and can deliver to the user's desktop selective resources based on user or community developed profiles. Such systems save the user effort by alerting them to requirements as and when they need them and can be used to create and sustain virtual and real research groups, to monitor the output of specific annual conferences, training and similar opportunities and to identify citations, particularly to your own research.

\section{New Information Search Scenarios}

So an effective system ought to integrate all these new technologies into a unified organisational information system but before I stress the efficiencies to be gained to too great an extent, it is worth pausing for a moment to consider the alternative. Because, 
much of the above assumes the classic model of information searching whereby words are entered into the system and through some process of comparison information resources are retrieved. There is an alternative view which says that users simply do not work like that - that they are happier addressing a specific subject collection, which they know will go some way towards answering the kind of problems they have, rather than addressing the whole of 'cyber space'. They may want a common interface but users may not be easily diverted from historical patterns of usage towards more generalised searching just like that.

The notion of searching out a specific title is also disappearing and my guess is that the bundled journal collections are illustrating new ways of information searching whereby value stems less from the quality markers such as peer review, reputation, layout etc and more from ease of access, ease of display and the quality of the descriptors which ensure adequate retrieval in the first place. The bundles will be different to what they once were and will be defined not by publishers or links from secondary services but by ways in which librarians et al. choose to parcel them up. Many current aggregations are either historically based, that is based around pre-existing print collections or the consequence of consortial arrangements. What are needed are aggregations based around institutional user needs and refined by actual usage.

And I also believe there is another sea change in searching as a result of the web: that is that the simplicity of moving from item to item. This again suggests a shift from the classic search and retrieve paradigm to structured browsing based on citations and links. The development of standards such as Open URL and SFX are testament to that. And as an extension of that is the opportunity to use user feedback (in the sense of user comments or recommendations) to guide the search process. How many users have looked at this article? What did they think of it? (Lynch 2001).

So we are left with new paradigms of usage with new balances between:

- Generalised searching vs. subject/searching v personalised

- Collection vs. titles

- Search and retrieve vs. citations and links and recommendations

\section{Authorisation and Authentication}

A third technical issue, which might incorrectly be considered trivial, is that we tend to know very little about who the user is. In the electronic domain this is not a simple question - we need assurances as to the fact that users are who they say they are, particularly if we are dealing with licensed resources where we need to give guarantees about access. Users must be suitably validated by some organisation and we must have systems in place, which permit them to do only what we would wish. The first level of that is authentication which is the process of identifying users on the network and is usually brought about by a combination of username/password challenge or IP domain 
search and restriction. There are more sophisticated accreditation systems that are coming, but are relatively little used in the library sector, and are more common in ecommerce applications; there will be a need to be more robust if we want to be involved in such systems. Once we have identified who someone is, there is a secondary process of authorisation, which essentially says what patrons can do once they have access. This is important for the managers of licensed resources and is critical in the context of the provision of e journals and the like. We might for example want to say that a user can access resource a but not $\mathrm{b}$ or $\mathrm{c}$, whereas all users in group $\mathrm{x}$ can access everything Even more complex arrangements could be envisaged across organisational boundaries where users may have different roles in different contexts; a researcher in one, a student in another and an employee in third and so on. There are emerging standards here such as Shibboleth in the US and PAPI in Europe. All of this leads to the notion that in the future we will need to know as much about the user as we do know about the object they are trying to find.

\section{Management of Change}

Managerial and change issues encompassing the move to digital libraries are substantial and involve both human and resource factors. Moreover, the changes are often difficult to predict, dependant as they are on the ever-changing nature of technology.

At the economic level, libraries in developed services are already aware of the problems, which derive from the need to maintain dual subscriptions to both electronic and traditional materials during this transitional period, which could last for some years. Users are often disinclined to make radical changes in their use of materials and resent electronic formats being imposed upon them; they also frequently require connectivity, machinery and IT/web skills to make best use of what is available. Moreover, spiralling journal prices add to the extra cost burden so that any potential savings the library might feel would be brought about by electronic delivery, are often difficult to realise.

One positive development has been the growth of consortial purchasing of bundled services which, as a consequence, should show some economy in budgets and also serve to democratise resource provision, especially for smaller institutions which can 'piggy back' on larger organisations resource requirements. However, we should be wary of purchasing policies which create redundancy in provision and that such bundled purchasing potentially enables access to large amounts of material which might be little needed (Friend 2000). An alternative is that of selling individual items for example, though at this point there seems to be little enthusiasm at library levels for end user charging or even for libraries to mediate in some similar arrangement. My suspicion is that this will come about in time, at least as a way of providing backup to core materials which the library cannot possibly buy.

Collective purchasing has had a dramatic impact and, providing consortia members are prepared to give and take, the benefits have been significant to all concerned. But this model may in itself not be transferable - it relates mainly to the licensing of scholarly 
data and works only in that context. There are limitations: licenses are still confused as to how they treat remote users; there are still a variety of authentication procedures demanded and even servicing different buildings is not always simple or accepted. The emergence of licensing has brought new business models but at the same time raised new questions for librarians and publishers alike. As Fred Friend has said "consortial purchasing is not the only feature of the new way of working, but is a critical feature that we have to get right. We will only get it right if the new business models provide enough income for publications to remain viable and enough of a saving to allow librarians to increase the range of information available to users (Friend 2000)."

Another major factor in the decline of the cost base has been the emergence of free journals (free to users) derived from a mixture of a drift to self-publishing on the one hand and Institutions asserting rights over their own IPR on the other. We are all familiar with the arguments and although it is my view that scholarly publishing will continue in its existing form for some time come, the mounting body of opinion which suggests that there will be a substantial increase in self-publishing or at least self-archiving can't all be wrong. For example universities are asserting rights over their own intellectual property, and the growth of e-print and other open archive initiatives are all potential ways of creating alternatives to the traditional scholarly publishing route.

I know you will counter with questions of quality but who is to argue that the current peer review mechanisms are not over elaborate or overstated? There are alternative ways of establishing authority and the current somewhat secretive process of peer review seems almost anachronistic in an age which is demanding more transparency. Lodging a paper in a MIT based repository to be accessed by many could be considered as prestigious an act as publishing in a journal that is read by very few And there are the emerging alternatives to peer review such as web site critiques, web citation, or myriad of site metrics as indicators of value. Moreover such knowledge repositories do not need to be merely passive - they are a potential focus for the dissemination of new ideas and could provide the same function of reinforcing academic status as that performed by scholarly journals.

Thus for the library manager, the economics of digital library delivery are complex and changing but I would argue, the longer term signals are largely healthy in that we may have at least seen the end of the spiralling costs of scholarly publishing from a mixture of those resources to which access has been negotiated, those electronic papers which have been defined as having a requisite level of quality to those which have been self archived by the author including adding in suitable descriptions so as to be retrieved through agent or similar technologies.

What then does the library manager need to do to ensure this shift to electronic delivery is as smooth as possible? What are the factors that need to be addressed? I've categorised my own views under four distinct headings which derive from the analysis above. These are strategic management, procurement, staffing and staff development. 


\section{Strategic management}

To bring about a transition to new forms of library suggest that the library manager should provide clear and articulate vision as to what the service might look like, how it might perform and how it will be evaluated at some future time. It should not be too far fetched or so far beyond the imagination of staff as to preclude its acceptance, but it will be a matter of driving the service forward and ensuring that those charged with delivering the change feel some ownership of it. As importantly it will need to encompass the views of the users, many of whom may wish to retain a traditional perspective on library delivery. Strategic plans will need to be sold on to the client base and achieve at least a respectable level of acceptance particularly from the executive, though in the end it may not gain total acceptance of everybody within the organisation.

Thus the library manager involved in strategic management must be very focused and the vision should be reinforced to the staff at all levels

\section{Procurement}

I've already talked about the economics of e-services and this could well imply a difficult period of increased expenditure so as to achieve medium term economies. As we have seen, collaborative purchasing with like minded libraries is one way forward, and works best between libraries with similar purchasing power or similar clientele so the charges levied on constituent members begins to be equitable. Consortial approaches can also be used to develop digital content, underwrite the cost of digitisation of material requiring conversion and so on and are likely to become more a feature of library services as they become more distributed.

\section{Staffing}

Perhaps more critical than any of these is to ensure that staff structures are in place which will meet the new challenges of electronic delivery. This will imply analysing every function within the service and asking the question, is it appropriate to continue to work in this way or are there alternatives that will help us achieve the strategic goal of delivery mechanisms? The nature of the core business of a library will change and functions such as cataloguing, which it could be argued has been the absolute foundation of libraries for the past hundred years or so, might well be achieved by subsidiary agencies such as National Cataloguing centres or global utilities. Technical services departments may have to find alternatives roles which could imply cataloguing Internet resources, though even this begs the question would it be better done co-operatively. It would be foolish to achieve economy in traditional cataloguing methods merely to replace it with another format and the development of the portals render this unnecessary. Many library staff will need to be re-skilled, both to ensure their knowledge and increase awareness of the accent in user support. Librarians will also need to promote themselves as knowledge managers, as web information managers. 
In summary we are going through a period of rapid change in the delivery of library services and need to re-think and constantly re-invent what we are. The library of the future will be as concerned with adding value to information resources and providing support and guidance as it will with acting as custodians of print material.

\section{Library Futures}

Will libraries in the future disappear entirely? Perhaps that depends how we define library: it could be a physical space, it could be a concept, it could be through its functions (Rusbridge 1998). As we have seen, the concept of a library as a collection of information sources defined by certain boundaries will remain, the boundary definitions will be more complex, deriving as much from consortial deals, usage issues and historical commitments as to collections within a building. The digital library will be a more fluent concept capable of continuous change and modification and even defined by the end user as much as by the librarian as intermediary

Much of this suggests that though there are tasks here in selection and procurement, they are becoming less pronounced, so that old style collection management is conceivably becoming redundant.

\section{Libraries as Space}

Libraries as a physical environment seem on the surface the least likely to exist in a digital future. Access to web services can be got from most places with adequate connectivity, which, with the increasing impact of mobile communications, means literally anywhere. Digital libraries will be free of the constraints of delivering audio and graphics and universally portable as individuals become able to access and maintain their own institutional view of the library. The counter argument goes that we still need spaces where users can come together, even if they are working independently, and which are conducive to long periods of screen use, are ergonomically designed, and have in place support systems and navigational help together with an associated output devices such as colour printers or high definition screens. These centres are already emerging as Internet cafes, resources centres, learning hubs and so on. Moreover, such centres are likely to coexist with more traditional provision permitting ease of use.

\section{Library as function}

If the core process of libraries is organising the information universe to enable easy access by users then we can argue that libraries have an unchallenged role to provide the relevant tools for that to continue in the Web domain. Building Web portals, creating and adding value to Web resources are all central to future systems. It implies customisation of resources, rights management, re packaging and re formatting and so on. We will need to be active in identifying content, disseminating and re presenting resources to suit different audiences and markets. It is all about becoming more user centred and less collection focused or function dominated. 
Libraries will need to bring higher levels of support to a user body which is becoming more distributed. Indeed if you imagine that all libraries will have the capability of delivering most anything then the level and quality of support, the level of customer support and service may well be the central determinant as to whether a service is successful or not.

Part of that agenda is Information Literacy; a need to train our users to not only search for themselves but also to discriminate and evaluate amongst resources which are increasingly plentiful but, as I have described, of dubious quality. This can be group based, one on one, through technology or traditional - it doesn't really matter. What is important is that as a task it becomes central to our role as knowledge broker.

\section{Summary}

To try and summarise, it seems to me that the shift that is taking place is away from the management of physical resources towards exploitation, support and the creation of pathways and links to support our mission of supporting research and innovation. Such services will be even more focussed on the user and his or her needs than before to the extent that they become highly personalised. Libraries will need to add real value to these processes in a way which is both measurable and unique.

And though I don't want to dwell on the role of librarians - in some ways we spend too much time contemplating our future whilst forgetting that the pressures of change we are currently experiencing are as much a feature of business and other professions as ourselves. But it does suggest to me that we need to reassess roles and the work force. We will need to realign staff effort into growth areas such as portal development and web support and at the same time re-address the centrality of other functions and look for a new skills set to meet these new challenges. We will need to form new alliances and partnerships - with pedagogic experts, with document managers, with publishers and other information businesses. It suggests librarians will need to be even more skilled than ever and keep on being reskilled as the technology changes ...the web won't last forever. It suggests a leaner, meaner workforce which is well paid and occupying the high ground of knowledge transfer, leaving the mundane and routine jobs to contractors or to be automated out of the system.

So finally, I advocate the following as being indicative of where we are heading:

- Libraries will become functions rather than places;

- And user focussed rather than collection centred;

- Information will become cheap but of questionable quality;

- Users will be more distributed yet we will need to know more about them; 
- Libraries will add value to information to provide more appropriate resources;

- The core processes of organising information will diversify into creating user focussed, personalised systems addressing all kinds of information;

- Libraries will comprise a mixture of professionals with changing boundaries and alliances;

\section{References}

Brophy, P. 2000. Towards a generic model of information and library services in the information age. Journal of Documentation 56 (2): 161-184.

Friend, F. 2000. Keeping your head in a revolution. Journal of Electronic Publishing 5(3). [Online]. Available: http://www.press.umich.edu/jep/05-03/friend.html [December 18, 2001].

Lynch, C. 2001. Personalization and Recommender Systems in the Larger Context: New Directions and Research Questions. Washington, DC: CNI. [Online]. Available: http://www.ercim.org/publication/ws-

proceedings/DelNoe02/CliffordLynchAbstract.pdf [December 18, 2001].

Rusbridge, C. 1998.Of arms and the man we sing. Ariadne 18. [Online]. Available:

http://www.ariadne.ac.uk/issue18/rusbridge/ [December 18, 2001].

1998. Towards the hybrid library. D-Lib Magazine July/August 1998.

[Online]. Available: http://www.dlib.org/dlib/july98/rusbridge/07rusbridge.html [December 18, 2001]. 